\title{
From of, to with, to and? Anti-disciplinary exhibition making with art and anthropology.
}

\author{
CLARKE, J.
}

2020

This is an Accepted Manuscript of a book chapter published by Routledge in "The Anthropologist as Curator" in 2020, available online: https://doi.org/10.4324/9781003086819-8 


\section{The Anthropologist as Curator}

\section{Click here to enter text.}

\section{Chapter 8}

From Of, to With, to And? Anti-disciplinary exhibition making with art and anthropology

\section{Click here to enter text.}

Dr. Jen Clarke

Much has been written about contemporary art's 'appropriation' of anthropological methods since Foster's influential critique 'The Artist as Ethnographer' (1996), however most discussions continue to focus on the nexus of art and ethnography, or artists' critical interventions in museums (e.g. Grimshaw and Ravetz 2015). Appropriation, from the Latin 'to make one's own', may be 'one of the most basic procedures of modern art production and education'(Verwoert 2007: 1). Nonetheless, perhaps because of increasing tensions between autonomy and heteronomy in art (Buckner 2013; Sansi 2015 , the appropriation of art by other disciplines is felt as a 'colonization' or 'invasion', terms normally reserved for acts of cultural imperialism. While interdisciplinary collaborations can be clear-cut, such as commissioning an artist or designer to bring scholarly knowledge to wider publics, increasing 'impact', transdisciplinary (or anti-disciplinary) 'experimental' fieldwork methods have also become popular, even part of mainstream anthropology, which surely already employs inventive tools and technologies in exploring alternative formats for anthropological knowledge. Anthropologists now regularly draw on techniques and representational devices from art or design, 'border crossing' between anthropology and art (Schneider and Wright 2006, 2010; Schneider 2011), to create novel outcomes or facilitate discussion as 
the rise in 'labs' at international conferences attests. Relatedly, as lines between 'social practice' in art and social research blur (Sansi 2015), anthropologists are increasingly taking on curatorial roles in contemporary art settings and/or employing artistic methodologies in exhibition-making. This chapter explores some dynamics of anthropology and art practice in this broad context by discussing specific experiences of being 'curator' and being 'curated', looking at forms of identity, knowledge and, warily, aesthetics.

With the interchanging and muddling of roles between artist and curator, it is now common practice that artists work as curators (Filipovic 2017). And it is increasingly the case that anthropologists, without academic training in art but interested in horizontal practices, take on the mantle of curator or artist, and claim this work as art. However, using the term 'curation' can be problematic, since there are significant differences between being a curator and the act of curating; an opportunity now open to many 'dilettantes' is the 'product of a profound shift in the definition not only of the curator but of the artist and the critic' (Kowalski 2010: n.p.). Border crossings prove difficult in practice, not least because one often begins full of assumption (by which I mean ‘assumption' as not only the presuppositions involved, what is tacitly understood, and expected to happen, but also the assumption of responsibility. Such difficulties, as I shall describe, are, I think, central to what it means 'to curate' or 'be curated' in specific situations. Referring to the etymological origins of the verb, the Latin curare, to care for, has also become prevalent in curating as a critical practice (Obrist 2014; Krysa 2015). While these notions converge convincingly with the ethics of anthropological fieldwork, at the same time I am aware of the potential for naivety about the politics involved, 
and the risk of being patronizing. In what follows I reflect on working collaboration with professional artists, making exhibitions, doing exactly this: claiming work as art and negotiating naivety. I consider two very different experiences, one that, for me, was instructive because it failed, and another that I see as relatively successful, and the questions thrown up about disciplinarity and knowledge, representation and aesthetics, questions that can be too easily discounted in inter- or anti-disciplinary undertakings. In describing the work I pay attention to two particular things: the presence and use of text or contextualization, and the use, understanding and interpretation of materials, which arguably distinguish art from anthropology ( Krysa 2015: 427-8). I begin by introducing an anti-disciplinary project Knowing from the Inside (KFI) that I was fortunate to be part of, before recounting two experiences of exhibition-making I undertook as part of the project, with lofty ambitions towards the 'refunctioning' of anthropology through collaboration (Marcus and Holmes 2008; cf. Korsby and Stavrianakis 2018). Although my collaborators gave permission for me to write about the exhibition, I have depersonalized details in order to work through and take ownership of my learning and how that informed subsequent practice. I also hope to avoid simple 'Capital-C' Criticism - my understanding of this is influenced by the curator Irit Rogoff's definitions: 'Capital-C' Criticism is about making value judgements and critique is about examining assumptions, but criticality aims further. Though 'a contingent and not entirely satisfactory term', criticality is about recognizing the limitations of one's thoughts and "living things out" [...] as opposed to pronouncing on them' (Rogoff 2006: 2). Three years later, for my final exhibition for the project, my work was curated by an artist, subjected 
to an art-school-like 'crit' as part of the 'show'. I share some of the conversation below, before reflecting on larger questions these experiences brought forth.

\section{'Knowing from the Inside'}

As a postdoctoral research fellow for the KFI project led by Tim Ingold, I worked with a multitude of artists, academics, designers and others who shared an interest in 'reconfiguring relations between practices'. Instead of treating artefacts as completed objects analysed retrospectively to determine meaning, our project explored generative currents of materials and the experience of practitioners together - thus, 'knowing from the inside'. We experimented with forms of knowledge, approaching knowledge as something that 'grows', as Ingold describes, from practical engagement, thinking with, from and through things (2013). Our project was anchored in anthropology but operated through collaborative sub-projects working with creative practices, without insisting on distinctions between theory and method. I see this approach as 'anti-disciplinary' and a form of 'research creation', working at the intersection of art practice and theory, attuned to process (in a Whiteheadian sense) rather than output (Manning 2016). A major theoretical concern for anthropology, practice provided us with a way to avoid intractable debates in philosophical aesthetics, though I have found myself caught up in them to some extent, as this chapter demonstrates. It was also a means of overcoming distinctions between acts and objects, and focussing on process, as well as allowing a broader reassessment of forms of representation and knowledge. 
As Ingold (2018b) later argued, more than any other discipline in the social sciences, anthropology is about learning how to learn, and the basis of our collective experiments was playful exploration of thinking-through-making, learning by following along with what is going on with material(s) where knowledge is produced through bodily practices such as dancing, weaving and drawing. While others worked with eco-building or laboratory theatre, to cite two examples, my work for KFI emphasized the incorporation of contemporary art practice ${ }^{1}$ as a vehicle for research, working with media/methods including printmaking, performance and site-specific installations, through a series of international residencies and exhibitions. Occasionally my artworks were sold (half of the proceeds going to the gallery), their price determined by a curator, ostensibly crossing into professional practice.

Speculative Ground (2014): from curation to commission Art practice and exhibition-making, including multiple if modest forms of curating, have always been part of my research, including 'durational' residencies and exhibitions in conventional art gallery settings as well as 'alternative' sites. The exhibition Speculative Ground, in 2014, was a fringe event for an anthropology conference, a project emerging from earlier collaborations with a fellow anthropologist who works with architecture and art, and an environmental artist with whom I had cooperated in a variety of ways. The exhibition included two forms of curation, though this was not a term we used at first. As academics with full-time salaries as well as generous budgets for fieldwork my colleague and I did not seek funding for our curatorial work as we had been privileged to do in other circumstances. We developed a 
proposal for funding, gaining additional funds to cover standard Scottish artist fees for the artist and her collaborator, a choreographer, as well as material costs. It is still too rare that artists receive standard artist's rates; ensuring they would be properly paid meant, we hoped, establishing a strong foundation for the project, acknowledging a common inequality that can sneak into interdisciplinary research projects that engage independent researchers and artists: money.

The exhibition consisted of two elements. First, a curated display of 'proposals on paper' or visual 'provocations' - critical and creative engagements with the Scottish government's recently published Land-Use Strategy. Involving clearcut curatorial responsibilities, we lightly curated the work; in the publication we wrote that we were not driven to judge works by artistic merit but hoped to find common ground between the submissions and how they illuminated our understanding of the issues, acknowledging different value-systems and visual languages. For the second part we intended to develop a collaborative approach, combining methods across art and anthropology, but in practice it operated as a commission, language the artists employed in subsequent descriptions. It began on the banks of a river in the countryside. During our first meeting the choreographer (whose first degree, notably, was anthropology) presumed the anthropologists would act as 'expert commentators', inviting us to observe the artists' improvisatory practices and write accounts of it. Perhaps I did not do a good job of explaining myself, or my methods, but after making clear this was not my approach we were left in a space of uncertainty. Having promised 'shared-investigations', the presumptions about what anthropologists do, and what artists do, revealed 
profound differences. Without sufficient time to develop an understanding, our predicament was aggravated when the anthropologist and I later used the term 'curation' to describe our role in interpreting materials.

'Sticks and stones ...' (materials)

Inspired by the riverbank ecology, we had hit upon the idea of attending to interruptions and obstructions as a way of approaching entangled interactions between living and non-living elements, and their more-than-human timeframes. The artist trained in environmental art was especially sensitive to this. Environmental art is about making work in and for other contexts, balancing concept and media through an informed understanding and use of language in materials/media as well as ideas. ${ }^{2}$ As we explored the exhibition space, responding to the context, the building interior (one wall covered in smooth, grey stones, presumably manufactured) as well as the riverbank, my anthropologist-colleague made a suggestion about producing stone-like weightless objects from synthetic materials: though a mere suggestion, with interesting connotations, this was anathema to the artists. It was, and not in a good way, 'amateur'. It is not that artificial materials are dismissed in contemporary art, but rather that, for them, the work was not about the question of materiality in that sense. In their final work the artists displayed 'real' stones alongside audiovisual documentation of dancers performing with them, shaping their bodily practices. Their work, in line with British traditions of environmental art, and the phenomenological spirit of the KFI project, nevertheless exposed a schism in our 'ways of seeing'. As Grimshaw and Ravetz point out: 'If anthropologists have long been alert to interlopers of one kind or another, artists are equally sensitive to work that appears to resemble 
their own practice but fails, in their judgment, to be the real thing' (2015: 4278).

Ultimately we developed entirely disconnected works for the exhibition. The artists made work about the specific ecology of the riverbank, bringing it into the exhibition space, through the materials and work they (re)presented. Instead, having failed to find a way in to working together with the riverbank, we chose to respond to the space (an academic building) as well as the conference theme - the Scottish Enlightenment - in conversation with our own emerging research. Having just returned from fieldwork in Japan, responding to the aftermath of the 3.11 disaster, I was working through my response to complex gender politics (see Clarke 2019). The Enlightenment thinking is arguably marred by anti-feminist discourse of philosophers such as David Hume, and I wanted to produce experimental 'interventions' to the specific site responding to this. I drew on poetry by William Blake, characters and lines from his poem The Daughters of Albion, which was inspired by Mary Wollstonecraft's A Vindication of the Rights of Woman. I used copper wire, beeswax, silk thread and Japanese paper combined with objects found on site, responding to the light - and the stains on the walls. I made a woodcut print several metres long, wrapping the wall, based on my drawing of a dense entanglement of power lines (that in Japan cross every street overhead) on almost transparent Japanese paper made from abaca. Next to the works I displayed detailed interpretation, for example botanical descriptions and the properties of abaca, the preferred material for dielectric materials, used in diverse products from power-transmission ropes to teabags, hats or vellum; a sheer overabundance of material and material detail. 
Palimpsests and Remnants (2017)

Three years later my final KFI exhibition, Palimpsests and Remnants (2017) explored relationships between process and objects in art and anthropology. This was my sixth in a series of exhibitions and residencies in Japan, Taiwan and Scotland in that period. By then my work had been curated in a number of different ways, including in a commercial gallery. I had performed and exhibited collaboratively with artists and others. For this exhibition I invited Alana Jelinek, a London-based artist and theorist whose participatory projects I had been involved with for a number of years, to act as curator as we are both interested in facilitating diverse forms of audience engagement and participation. This exhibition was also site-specific in a limited sense - the work responded to the idea of a museum-turned-gallery as a metaphor as well as the 'aesthetic' of the space. (The Anatomy Rooms where the exhibition was held was previously a university anatomy department, and was now an artist-led studio; the space I was using still furnished as the Museum Room.) As Alana described in her curator's statement, the exhibition was 'a dialogue' between the artworks, artefacts and detritus of my practice for the past three years and Alana's artistic practice, here as curator, 'paying attention to the space its formal and spatial qualities, working with its histories of use, allowing nails, electric cables and other remnants to be present'.

The exhibition had two related parts: Remnants, a display of selected 'detritus' from my workshops, alongside collaboratively produced Japanese calligraphy, and Palimpsests, an installation addressing processes including cyanotype, ikebana and mixed-media printmaking. Ikebana, a Japanese tradition of flower arrangement with roots in Zen Buddhism, is an act of consolation and 
remembrance, its principles expressed through relationships between materials, space and time. Creating 'portraits' of four female friends who made it possible for me to live and work in Tohoku, I also wanted to emphasize the hybrid nature of ikebana - as an object, considering the vessels and materials, and as a practice. Ikebana is inherently temporal - the material's plant life subject to decay and decomposition, but also given the emphasis on the gestural, embodied experience of making. For Remnants I wanted to examine the weak materiality of the quasi-objects produced during workshops, then archived or abandoned. I was interested in considering through the language of materials the sense of neglect, or lack of care, in the way stuff was discarded ('archived', or not) in a context where the 'care' of curare was often cited. Where was the value of 'the work' located? How did this relate to how things are given value in ethnographic or art collections? My idea was to produce an exhibit that dealt lightly with this interesting problem, exploring different hybrid forms (Jones 2015), without heavy use of explanatory narrative or interpretation.

The crit Anthropological exhibitions rely on contextualizing devices more than art (though art's interpretation strategies are complex in other ways). Our aim instead was to let the work 'speak for itself', allowing visitors to 'listen' to the work through the way it was displayed and how space was used. We did not use language to interpret the work beyond short artist and curator statements. Instead, we held a 'crit', a group investigation where a range of interpretations about what the work signified or evoked was discussed. A 'crit', or critique, is a crucial part of fine art education in the disciplining of the person as an artist. 
The audience, a group of about twenty artists and academics, were led in discussion by Alana while I remained silent. The two interweaving sections were recognized as process and 'archive'. As one person said, the trick is 'within the fizziness of such a rich process that feels like years of work' how to 'guide us to precise moments'. Alana drew out what these might be for different people: the intensity of the cyan blue [cyanotypes] with celestial references 'pulled back into now' by the use of natural materials; the plant matter, 'still alive, these things are alive' that gave a sense of 'the becomings after life' as well as of waiting, and, in the tension between natural and nonnatural, questions of temporality. For others this feeling was echoed in the use of the chairs, where the ikebana 'portraits' literally sat, reminding one artist of the representation of domestic Dutch interior still lives, with flowers becoming memento mori, reminders of (our) death. For others, the placing of the chairs created a polite distance, incongruous against the rest, so much 'out of order'. The work raised the question of how to restitute 'process'. There was, literally, as an anthropologist remarked, no map, no contextualizing text. While everyone noted the tactility of making, against this, in Remnants we chose to include the injunction 'do not touch' for objects on display; someone said this 'does something' to the engagement, turning the materials into museum pieces - or evoking their desire to be. The audience speculated on the material and the lack of framing, sensing desire from fraying, soft edges of paper, but also a lack of control, a sense of destruction, veiled within multiple layers of images, images of disaster and regrowth. For some the exhibition conveyed 'authoriality' along with the strong sense of being 'in progress'. For others, the same work conveyed a lack of authority, even randomness; for 
them the message was 'things happen to us' - just as the disaster did in Japan. Signs saying 'fragile' and displays including packaging materials gave a sense of things travelling, of distance and the need to protect, though for others this felt 'like a conceptual joke'. It all clearly conjured Japan, via paper, ikebana, ceramics, calligraphy, but 'not a pristine' Japan. An anthropologist (who knows me and my writing but not my visual work) commented that the work was clearly also about the artist: 'it all leads to her, what constitutes Jen'. Such thoughtful, verbalized interpretations raised questions about art, knowledge and authorship. These interpretations are also potentially wider than those we could have encouraged through tighter interpretation; and yet for me the experience of making, the exhibition and the crit produced knowledge irreducible to language. 'We know more than we can tell' as Polyani insisted (1983). Working with Alana, and with the principle of waiting for the work to 'speak', allowed that. It was a way of 'provoking' the field, rather than representing what was already given, what I already 'knew'; and thus a means for me to rethink my own practice(s) and position from a different point of view - which returns me to the work of anthropology.

Self-creation and professional identities

Working between art and anthropology, easy to claim in theory, is difficult in practice. The first exhibition was successful by some measures, but for me it was a failed project. Whether the work failed is not necessarily for me to say (in hindsight, it worked as a kind of provocation, though it was complicated rather than complex, in terms of materials and their interpretive and poetic framings, as well as in execution). I can say I did not properly account for the audience (thus it would fail as art, according to certain definitions; Zangwill 
1999). Collaborations with anthropology should begin by questioning existing relations. We failed by not questioning ourselves, working from assumptions, asserting expertise. Part of the language of such projects is the use of the word 'curator', which, for the artists, implied an imbalance in authority; a detail, but, as Roger Sansi has suggested, 'In the end, border hunting often appears as the nervous reaction of those not quite sure of the grounds of their territory' (Sansi 2015: 137). Was this failure the result of 'nervous reaction', sheer defensiveness? What happens to a collaboration when it becomes a 'commission'? The problem relates to the politicization of professional identities. As Mouffe argues, these are not pre-given but discursively constructed 'the result of processes of identification [...] the question that arises is the type of identity that critical artistic practices should aim at fostering (Mouffe 2007: 4). What type of identities might we foster? Nowadays artists are sometimes referred to as 'artworkers', recalling the post-Fordist worker, unable to separate work and life, identity and job. This blurring of art and 'life' might be the utopian ideal for contemporary art (Jelinek 2013), but what is at stake is our 'capacity to define ourselves' (Sansi 2015: 151)? The art historian and feminist Angela Dimitrikaki has identified how being an artist or curator:

means having a professional identity, associated with remuneration for labor [...] this predicament is not only relevant to women. Yet having been excluded from it for too long, women in art tend to be more attached to this professional identity. For many women, being recognized as a professional artist (or indeed a professional anything) is a hard-won gain. (Dimitrakaki 2018, n.p.) 
In this light, it makes sense that the artists insisted on their professional role (especially these women artists, seeking to further establish themselves in an academic setting in which they felt unable to speak). It is also the case for Alana Jelinek (2013), who argues that artists should 'police the boundaries' of art, following Rancière's definition. As Sansi points out (2015) professional hurdles are associated with being an anthropologist/academic too: advanced academic production, a Ph.D. and so on, at odds with deskilling and amateurism. Reflecting on these issues I came to consider whether identity, self-creation through dissensus, could be positive thing. Might this lead to a level of self-reflexivity, generative of ... something else?

I am driven by a desire to develop myself as well as my skills, alongside those I work with, and learning enables me to share with others. Anthropology as learning (and learning to learn), a form of self-development, can be aligned with art; both promise self-creation. Making art can be a way of making oneself, a 'subjective intervention' that 'recreate[s] the self in the same movement by which it objectifies something beyond that self' (Leach 2007: 108). More than this, in the art world, art-making is considered desirable selffulfilling work (Dimitrakaki 2018, n.p.), one excuse when artists are expected to work without pay! Nevertheless, both disciplines are dubious about research intersecting with self-expression, which, while evident in art education, is disparaged. This recalls debates in anthropology about autoethnography, should the researcher 'loom' too largely in the work (Venkatesan 2010).

All the artists referred to here define their identity by asserting a particular way of seeing, through working with material, the value of art as a skilled way of 
generating knowledge. In one sense, differences in terms of aesthetic decision-making (formally, as well as in terms of content), may have betrayed a lack of training, even at times an amateur approach. To be amateur suggests sheer enthusiasm, doing something for pleasure, but it can also mean something unprofessional, substandard. As Sansi advises: 'if we accuse someone of being an amateur, we make a number of assumptions on what is valued as work. So we probably need to get back to these assumptions' (Sansi 2018, n.p., my emphasis). So, what is valued as work, or, indeed, as knowledge?

\section{A problem of knowledge forms?}

It is clear that anthropologists do not value 'methods' and media in the same way artists do. This is not to impose a hierarchy, ideally there is no hierarchy of knowledge that depends on the media used, whether for anthropological representations or other forms, as Sarah Pink argues (2012): knowledge produced through one medium can be related to, but cannot replace or be replaced by, knowledge produced through another; art practice then offers a unique mode of forming knowledge. An image I return to when trying to describe what art does and what anthropology does has to do with folds and folding: for me anthropology seeks to unfold: to set out, open up, explain, each unfolding unique to those who encounter it; artworks, conversely, are folded in complex forms, like gifts, wrapped, they demand something else of the viewer.

Anthropologists working with art tend to fall into two categories - borrowing artistic methods and methodologies (as in 'ethnographic conceptualism') or making art/artists the subject of investigation using established 
anthropological methods (Jelinek 2016); what I call anthropology with art versus anthropologies of art. An important difference between these is practice, clearly. In my experience it is risky to employ artistic methods and to try to call the work 'art' without understanding values and politics in art. Whether 'borrowings' result in work that can legitimately either be called anthropological or presented as 'real' artwork has been the subject of lively debate in visual anthropology for decades (Grimshaw and Ravetz 2015). Jelinek (2016) suggests most 'multivalent' efforts of exhibition-making fail, as art. It is true that contemporary art is less and less defined by media, and that while many trained artists have technical expertise, artists often 'work with' media they have not trained in, as Sansi points out (2015). But, as Jelinek argues in This is Not Art (2013), what disciplines artists is not technical expertise but training that is a form of self-development within the particular 'habitus' of practice (usually the art school), including scenarios such as the 'crit'. What I have learned from being curated by and working with Alana is the value of forbearance, or a 'moral aesthetic' (Carrithers 2005): a capacity to hold one's own view while seeking to understand another's, being informed by but not determined by another; a disciplined way of being.

So, while not defined by technical expertise, having the skills to 'treat a material so that it becomes a medium of expression' as well as a theoretical or conceptual basis for work matters (Eisner 2008: 9-10). Art education thus is not only about technical skill (something that the long-running debate about what constitutes art versus craft also picks up on) but also tacit knowledge. This focus on knowledge, albeit the sorts that are difficult to declare, might be problematic for those who work with the concepts of amateurism, 'un-learning' 
or anti-disciplinarity (central tenets of the KFI project) in their border crossings. However, un-learning can be seen as learning without explanation, as we sought to do with the 'crit' - echoing Rancière's Ignorant Schoolmaster; not the opposite of knowledge, but an approach. It is certainly an important concept for rethinking standardized notions of work as well as knowledge, central to movements in higher education resisting the corporatization of universities, and art practices that seek to 'un-learn privilege' (as the Casco Art Institute, Utrecht, does, drawing on postcolonial theory and feminist art practice). Interestingly, for Grimshaw and Ravetz (2015), art is predicated on a state of 'not knowing', and it is this challenge to knowledge that makes the use of art 'disruptive' to anthropology, always focussed on generating 'new knowledge'. Directly opposing 'knowledge' and 'art' is, I think, problematic, as I have suggested. Indeed, the question of whether one gains knowledge through art is a long-standing one in the philosophy of art, certainly since Plato (Gaut 2003). But if we understand not knowing as a way in to knowing, art as knowledge (or knowledge 'forming' as Alana Jelinek argues), things open up.

The idea of art as knowledge is also not new. Carl Hamburg argued in 1952 that claiming art as knowledge could 'at worst' be seen as avoiding the problem of distinguishing them; but he posited a continuity between art and knowledge, if art is seen as 'comparable to other modes of human understanding' (1952: 2). Artists are increasingly getting involved in the debate, since there are important ramifications for the ways art is valued, but also for how 'research' in studio practice might be conducted (Herrington 2014). This is a burning question in art schools in Britain today and, until 
recently (2011), visual and material 'outputs' by artists were not actually recognized as 'knowledge' by the Arts and Humanities Research Council in Britain. For creative practices, writing around the work that 'contextualizes' is most often how something is judged as making contribution to 'knowledge' and thus understood as research. In recent research I have begun exploring what constitutes research across art and design, which seem qualitatively different. Ingold, who writes vociferously against ethnography as the basis of anthropological knowledge (2014), also challenges the accepted assumptions that ethnography is the primary method art and anthropology share (2018), returning us to where we began. Is contextualization necessary to constitute 'knowledge' through art? Specifically, anthropological knowledge? How shall we proceed, if we want anthropology to reject a scientific model of knowledge, and take inspiration from art practice instead, as Ingold (2018a) argues? What might the acceptable outcomes be, and what would they look like? 'Real' art, or hybrid forms? If the role of the 'expert' now is 'to establish points of discussion', not to 'produce knowledge', as Rabinow describes, following Niklas Luhman (2008: 56), once we locate value in practice and process, even refusing 'explanation' in favour of 'un-learning' and being open to not knowing, does it matter what comes out at the end?

Aesthetics? (Content and form)

It is precisely the fact that anthropology is constituted by knowledge that is responsible for its 'underdeveloped aesthetic'. And, if anthropology 'with' art is predicated on art and anthropology's analogous ways of engaging with the world (Ingold 2013), this is only possible because it also 'followed a break with certain key assumptions about art and artists - specifically, the centrality of 
form, originality, the imagination, innovation and individuality' (Grimshaw and Ravetz 2015: 424). Aesthetics, identified as a key problem for 'ethnographically inflected artistic work', is overlooked, these authors contend, in favour of 'ethics', seen as 'a vehicle for content rather than an outcome actively shaped by an emergent play of content and form' (ibid.: 430). It would be an oversimplification to generalize that anthropology prioritizes content over form while art prioritizes form over content. While many argue art cleaved away from aesthetics long ago (Arthur Danto posits that this happened following the 'anaesthetic' 'ready-mades' of Marcel Duchamp a century ago), within contemporary art there remain manifold references to 'aesthetics' in practice and theory. But, as I experienced in the first exhibition, a lack of attention to matters of form "bewilders artists, for whom it is the aesthetic that holds the key to art's transformative potential' (ibid.). Thus, (re)introducing aesthetic issues into anthropological practices is not only 'deeply unsettling' but also 'potentially transformative'. That said, as a category of thought, aesthetics has been roundly rejected by anthropologists interested in art practice (e.g. Ingold 2013), perhaps partly due to the weight and complexity of philosophical debate regarding theories of beauty and experience (Bunn 2018). Important criticism (often from anthropology) has pointed to the limitations of classic European aesthetic theories, for example how the Kantian idea of disinterestedness limits understandings of nonWestern art and aesthetics (Marcus and Myers 1995). Basically, if aesthetics is reduced to the question of beauty or ugliness (as it can be, crudely, via Kant's notion of subjective judgement), then anthropology's approach to aesthetics differs, tending towards an understanding drawn from its Greek 
roots 'aesthesis', meaning 'perception'. I hold that subsuming aesthetic experience to perceptual experience (as Ingold arguably does) circumvents much of the politics of art.

For contemporary artists who use material as metaphor, aesthetics in practice is about relationships between content and material or form, finding a satisfactory way of 'resolving' a problem. And art, is about practice, not principles (Buckner 2013). Attempting to understand how aesthetics is used does not necessitate a reduction to formalism (there are both moderate and extreme approaches), but, as theorist Johanna Drucker describes, there has been a resurgence of 'formal voluptuousness' and 'material intelligence', which has revitalized conceptualism since the 1990s (2005: 77). The rising fascination for 'new' materialism is also impacting. It is inappropriate to generalize, since there are as many differences between artists' ideas about aesthetics as there probably are between art and anthropology; indeed, it is important to highlight debate within art. Anthropology does always recognize how contested aesthetics is, already, in theory (Marcus and Myers 1995: 14). And theory informs practice (informing theory ...). This does not mean that all artists work or see in the same way. Perhaps the 'problem' is not aesthetics but the politics of representation: viewed conservatively both art and anthropology might be seen as representing the world, out there, giving form to pre-existing 'content'. Contemporary art does not aim to represent but to perform, to make the world happen; joining in with this speculative attitude was both the premise and the finding of the KFI project (see also Sansi 2018). Convergences or conjunctions 
Convergences in art and anthropology can be seen in terms of inter- or transdisciplinarity. There are many definitions related to integrating or exchanging knowledge across subject boundaries (see Toomey et al. 2015). For me, the term inter- implies between-ness, open to points of contact, though disciplinary distinctions remain. Developing clearer understandings of 'resistances' as well as the convergences would help establish the ground for such 'hybrid' work (Grimshaw and Ravetz 2015). Trans- suggests a traversing of distinctions and a different kind of relation within a single practice (e.g. Laine 2018). Either might produce art that is 'anthropological', which Ingold defines via four principles (2018): generosity, open-endedness, comparativeness (why this direction, rather than the other?) and being critical, not in the sense of making judgements about things as they are, but speculative criticality. Perhaps the reification of 'pure' art or anthropology is the mistake; appropriation teaches us everything is hybrid, somehow (Schneider 2003). Could anthropology and art functioning as a conjunction, do something other than the 'hybrid' convergences of inter- or anti-disciplinarity? What outcomes are possible, when taking an approach that acknowledges debate, in both disciplines? What matters, crucially is producing work that 'speaks for itself', and legitimately satisfies conditions for both disciplines. For me, what I learned from these experiences curating and being curated was recognizing limitations, in myself as well, developing criticality in specific encounters, not seeking to resolve tensions theoretically, since any outcome, proposition or project is always dependent on the specific encounter. I learned to think of art anthropology and curation as 'an 'ecology of practices', a 'mode of questioning' that situates the relevance and limits of one practice in relation 
to the others, considering how knowledge gleaned from one field might be brought to bear on others (Stengers 2005). Divergent practices 'impinge upon' one another, a relational approach not unlike Rabinow and Marcus's (2008) notion of the contemporary; this does not preclude an understanding of roles, or professions, defined in disciplinary terms. I felt the first failure keenly, because valued relationships effectively ended. But it forced me to ask questions about how I wanted to work. Eventually I came to appreciate, as much as possible from an artist's point of view, why it matters that art might be considered as 'knowledge forming', tackling relationships between content and form, addressing materials and process, and what learning with these, with-or-and art, might bring to anthropology, as well as being reminded of what anthropology brings me.

References

1. Bunn. S. (ed.) (2018), Anthropology and Beauty: From Aesthetics to Creativity, Abingdon: Routledge.

2. Buckner, C. (2013), 'Autonomy, Pluralism, Play: Danto, Greenberg, Kant, and the Philosophy of Art History', Journal of Aesthetics \& Culture, 5.

3. Carrithers, M. (2005) 'Anthropology as a Moral Science of Possibilities', Current Anthropology, 46 (3): 433-56.

4. Clarke, J. (2017), 交流 Koryu, Aberdeen: University of Aberdeen, available online: https://knowingfromtheinside.org/files/koryu.pdf.

5. Clarke, J. (2019/forthcoming), 'Apocalyptic Sublimes and the Recalibration of Distance: Doing Art-Anthropology in Post Disaster Japan', in Philipp Schorch, Martin Saxer and Marlen Elders (eds), Researching Materiality and Connectivity in Anthropology and Beyond, London: UCL Press.

6. Danto. A. C. (1998), 'The End of Art: A Philosophical Defense', History and Theory, 37 (4): 127-143.

7. Dimitrakaki, A. (2018), Feminism, Art, Contradictions, e-flux journal, \#92 June, available online: https://www.e-flux.com/journal/92/205536/feminism-artcontradictions / (accessed 1 February 2019).

8. Drucker, J. (2005), Sweet Dreams: Contemporary Art and Complicity, Chicago: University of Chicago Press.

9. Eisner, E. (2008), 'Art and Knowledge', in J. Gary Knowles and Ardra L. Cole (eds), Handbook of the Arts in Qualitative Research: Perspectives, Methodologies, Examples, and Issues, London: Sage.

10. Faubion, J. D. and George E. Marcus (eds) (2009), Fieldwork Is Not What it Used To Be: Learning Anthropology's Method in a Time of Transition, Ithaca: Cornell University Press. 
11. Filipovic, E. (ed.) (2017), The Artist as Curator: An Anthology, Berlin: Verlag der Buchhandlung Walther Konig.

12. Foster, H. (1996), 'The Artist as Ethnographer?', in H. Foster (ed.), The Return of the Real: The Avant-garde at the End of the Century, 171-203, Cambridge, MA: MIT Press.

13. Gaut, B. (2003), 'Art and Knowledge', in Jerrold Levinson (ed.), The Oxford Handbook of Aesthetics, 436-50, Oxford: Oxford University Press.

14. Grimshaw, A. and Ravetz, A. (2015), 'The Ethnographic Turn - And After: A Critical Approach towards the Realignment of Art and Anthropology', Social Anthropology, 23 (4): 418-34.

15. Hamburg, C. H. (1952), 'Art as Knowledge', College Art Journal, 12 (1): 2-11. 16. Herrington, J. (2014), 'Can Knowledge Be Found in Works of Art?', Runway, Australian Experimental Art, Issue 26.

17. Ingold, T. (2010), 'Bringing Things to Life: Creative Entanglements in a World of Materials', ESRC National Centre for Research Methods NCRM Working Paper Series 05/10.

18. Ingold, T. (2013), Making: Anthropology, Archaeology, Art and Architecture, London: Routledge.

19. Ingold, T. (2014), 'That's Enough about Ethnography!', in HAU: Journal of Ethnographic Theory, 4 (1), available online:

https://www.haujournal.org/index.php/hau/article/view/hau4.1.021.

20. Ingold, T. (2017), Correspondences, Aberdeen: University of Aberdeen.

21. Ingold, T. (2018a), 'Art and Anthropology for a Living World', Public Talk, May 2018, École des Arts Déco, Paris, available online:

http://www.ensadlab.fr/francais-conference-de-tim-ingold-art-and-

anthropology-for-a-living-world-le-29-mars-2018-a-lensad/.

22. Ingold, T. (2018b), Anthropology As/And Education. London: Routledge.

23. Jelinek, A. (2013), This Is Not Art, London: I.B. Taurus.

24. Jelinek, A. (2016), 'Response: An Artist's Response to an Anthropological Perspective', Social Anthropology/Anthropologie Sociale, 24 (4): 503-9.

25. Jones, A. (2015), 'Material Traces: Performativity, Artistic "Work", and New Concepts of Agency', TDR/The Drama Review, 59 (4): 18-35.

26. Korsby, Trine Mygind and Anthony Stavrianakis (2018), 'Moments in Collaboration: Experiments in Concept Work', Ethnos, 83 (1), 39-57.

27. Kowalski, M. J. (2010), 'The Curatorial Muse', Contemporary Aesthetics, 8, available online:

https://contempaesthetics.org/newvolume/pages/article.php?articleID=585 (accessed 1 October 2018).

28. Krysa, J. (2015), 'The Politics of Contemporary Curating', in R. Martin (ed.),

The Routledge Companion to Art and Politics, London: Routledge.

29. Laidlaw, J. (2010), 'Agency and Responsibility: Perhaps You Can Have Too

Much of a Good Thing', in M. Lambek (ed.), Ordinary Ethics: Anthropology,

Language and Action, 143-64, New York: Fordham University Press.

30. Lambek, M. (2010), 'Introduction', In M. Lambek (ed.), Ordinary Ethics:

Anthropology, Language and Action, 1-38, New York: Fordham University Press.

31. Laine, A. (2018), Practicing Art and Anthropology, A Transdisciplinary Journey, London: Bloomsbury.

32. Leach, J. (2007), 'Differentiation and Encompassment: A Critique of Alfred Gell's Theory of the Abduction of Creativity', in Amiria Henare, Martin Holbraad 
and Sari Wastell (eds), Thinking Through Things, Theorising Artefacts

Ethnographically, London: Routledge.

33. Manning, E. (2016), 'Ten Propositions for Research-Creation', in: N. Colin and S. Sachsenmaier (eds), Collaboration in Performance Practice, London: Palgrave Macmillan.

34. Marcus, G. and Myers, F. (1995), The Traffic in Culture: Refiguring Art and Anthropology, Berkeley: University of California Press.

35. Marcus, G. and Douglas Holmes (2008), 'Collaboration Today and the ReImagination of the Classic Scene of Fieldwork Encounter', Collaborative Anthropologies, 1: 81-101.

36. Mouffe. C. (2007), 'Artistic Activism and Agonistic Spaces', Art \& Research: A Journal of Ideas, Contexts and Methods, 1 (2), Summer.

37. Obrist, H. U. (2014), Hans Ulrich Obrist: The Art of Curation, Guardian, available online:

https://www.theguardian.com/artanddesign/2014/mar/23/hans-ulrich-obristart-curator, accessed 1 October 2018.

38. Pink. S. (2012), 'Advances in Visual Methodology, an Introduction', in S. Pink (ed.), Advances in Visual Methodology, London: Sage.

39. Polanyi, M. (1983), The Tacit Dimension, Gloucester, MA: Peter Smith Publisher.

40. Rabinow, P. and Marcus, G. (2008), Designs for an Anthropology of the Contemporary, Durham, NC, and London : Duke University Press.

41. Ravetz, A. (2011), 'Both Created and Discovered: The Case for Reverie and Play in a Redrawn Anthropology', in T. Ingold (ed.), Redrawing Anthropology, 157-76, Surrey: Ashgate.

42. Sansi, R. (2015), Art, Anthropology and the Gift, London: Bloomsbury.

43. Sansi, R. (2018), 'Unlearning the Role Game: Artists, Amateurs, Historians and Neighbors in the Periphery of Barcelona', Field, 11, available online: http://field-journal.com/issue-11/unlearning-the-role-game, accessed 9 February 2019.

44. Schneider, A. (2003), 'On “appropriation”. A Critical Reappraisal of the Concept and its Application in Global Art Practices', Social Anthropology, 11 (2): 215-29.

45. Schneider, A. and C. Wright (eds) (2006), Contemporary Art and Anthropology, Oxford: Berg.

46. Schneider, A. and C. Wright (eds) (2010), Between Art and Anthropology:

Contemporary Ethnographic Practice, Oxford: Berg.

47. Schneider, A. and C. Wright (eds) (2013), Anthropology and Art Practice, London: Bloomsbury Academic.

48. Smith, T. (2009), What Is Contemporary Art? Chicago: University of Chicago Press.

49. Smith, T. (2016), 'Art, anthropology, and anxiety', HAU: Journal of

Ethnographic Theory, 6 (1): 371-402.

50. Stengers, I. (2005), 'Introductory Notes on an Ecology of Practices', Cultural Studies Review, 11 (1), March 2005.

51. Strohm, K. (2012), 'When Anthropology Meets Contemporary Art: Notes for a Politics of Collaboration', Collaborative Anthropologies, 5: 98-124. 
52. Toomey, A. H., Nils Markusson, Emily Adams and Beth Brockett (2015), Interand Trans-Disciplinary Research: A Critical Perspective, GSDR 2015 Brief, Lancaster Environment Centre, UK: Lancaster University.

53. Venkatesan, S. (2010), 'Ontology Is just Another Word for Culture', motion tabled at the 2008 Meeting of the Group for Debates in Anthropological Theory, University of Manchester, UK, in Critique of Anthropology, June, 30 (2): 152-200. 54. Verwoert, J. (2007), 'Living with Ghosts: From Appropriation to Invocation in Contemporary Art', in Art \& Research: A Journal of Ideas, Contexts and Methods, 1 (2).

55. Zangwill, N. (1999), 'Art and Audience', The Journal of Aesthetics and Art Criticism, 57 (3) (Summer): 315-32.

\footnotetext{
${ }^{1}$ Contemporary art is a very loose term. The art historian Terry Smith identifies three 'types': the spectacles of massive museums and art markets; postcolonial art 'of transnational transitionality'; and 'new modes of visual imagining'. The last is perhaps the most pertinent, if enigmatic (Smith 2016: 395). It is not my goal to further define the term, except to point to the idea that contemporary artworks can operate as acts of thought as Smith also suggests (2009).

${ }^{2}$ As it is described in the course materials of the Glasgow School of Art, Scotland.
} 